Supporting Information for

\title{
Free-Standing and Circular-Polarizing Chirophotonic Crystal Reflectors: Photo-Polymerization of Helical Nanostructures
}

\author{
Dae-Yoon Kim, ${ }^{\text {a }}$ Changwoon Nah, ${ }^{a}$ Shin-Woong Kang, ${ }^{b}$ Seung Hee Lee, ${ }^{b}$ \\ Kyung Min Lee, ${ }^{\mathrm{c}}$ Timothy J. White, ${ }^{\mathrm{c}}$ and Kwang-Un Jeong,,a
}

${ }^{a}$ BK21 Plus Haptic Polymer Composite Research Team \& Department of Polymer-Nano Science and Technology, Chonbuk National University, Jeonju 54896, Korea.

${ }^{\mathrm{b}}$ Department of BIN Convergence Technology, Chonbuk National University, Jeonju 54896, Korea.

${ }^{c}$ US Air Force Research Laboratory, Wright-Patterson Air Force Base, Ohio 45433-7750, USA.

*kujeong@jbnu.ac.kr

Synthesis of 4'-[6-(2-methacryloyloxy)-hexyloxy]biphenyl-4-carboxylic acid (1). The solution of 4'-hydroxybiphenyl-4-carboxylic acid (10.7 mmol), $5.0 \mathrm{~g}$ of $\mathrm{KOH}$, and $0.25 \mathrm{~g}$ of $\mathrm{KI}$ in $40 \mathrm{~mL}$ of ethanol was added into the $20 \mathrm{~mL}$ of 6-chlorohexanol. After refluxing for $48 \mathrm{~h}$, $2.5 \mathrm{~g}$ of $\mathrm{KOH}$ was additionally added to the mixture and stirred for $24 \mathrm{~h}$. After cooling to room temperature, the crude mixture was acidified with dilute $\mathrm{HCl}$. The precipitate was filtered and then dissolved in the $50 \mathrm{~mL}$ of 1,4-dioxane. The mixture was held at $0{ }^{\circ} \mathrm{C}$ and carefully added to a solution of $2.5 \mathrm{~mL}$ of triethylamine and $5.5 \mathrm{~mL}$ of methacryloyl chloride in $10 \mathrm{~mL}$ of 1,4-dioxane. The mixture was stirred for $24 \mathrm{~h}$ and poured into the $100 \mathrm{~mL}$ of distilled water. The product was extracted using $500 \mathrm{~mL}$ of ethyl acetate. After evaporating solvents, the resultant solid was refluxed in the $50 \mathrm{~mL}$ of acetic acid and recrystallized in the $10 \mathrm{~mL}$ of ethanol. The purified white powder was collected (yield: 63\%). ${ }^{1} \mathrm{H}$ NMR (400 MHz, DMSO- $d, \delta): 12.88(\mathrm{~s}, 1 \mathrm{H}), 7.98(\mathrm{~d}, 4 \mathrm{H}), 7.02(\mathrm{~d}, 2 \mathrm{H}), 6.05(\mathrm{~s}, 1 \mathrm{H}), 5.69(\mathrm{~s}, 1 \mathrm{H}), 4.13(\mathrm{t}, 2 \mathrm{H})$, $4.01(\mathrm{t}, 2 \mathrm{H}), 1.87(\mathrm{~s}, 3 \mathrm{H}), 1.65(\mathrm{~m}, 4 \mathrm{H}), 1.25(\mathrm{~m}, 4 \mathrm{H}) \mathrm{ppm}$. 

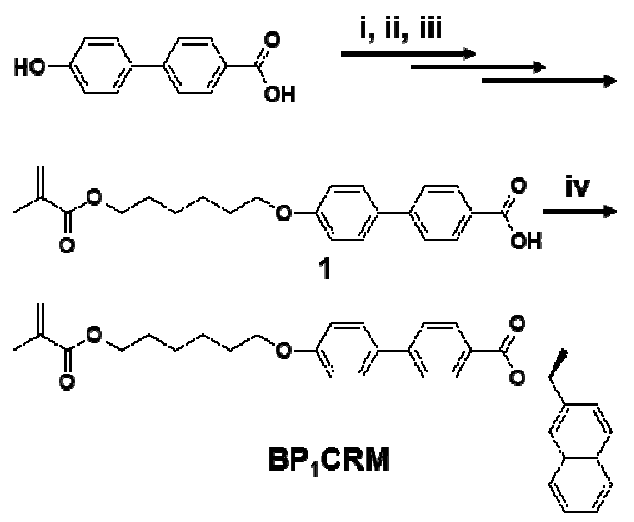

Figure S1. Synthetic procedures of $\mathrm{BP}_{1} \mathrm{CRM}$. Reagents and conditions: (i) chlorohexanol, $\mathrm{KOH}, \mathrm{KI}, \mathrm{EtOH}$, reflux, $72 \mathrm{~h}$; (ii) methacryloyl chloride, TEA, dioxane, $0^{\circ} \mathrm{C}, 24 \mathrm{~h}$; (iii) acetic acid, reflux, $1 \mathrm{~h}$; (iv) chiral naphthyl alcohol, EDC, DMAP, THF, MC, $25^{\circ} \mathrm{C}, 48 \mathrm{~h}$.

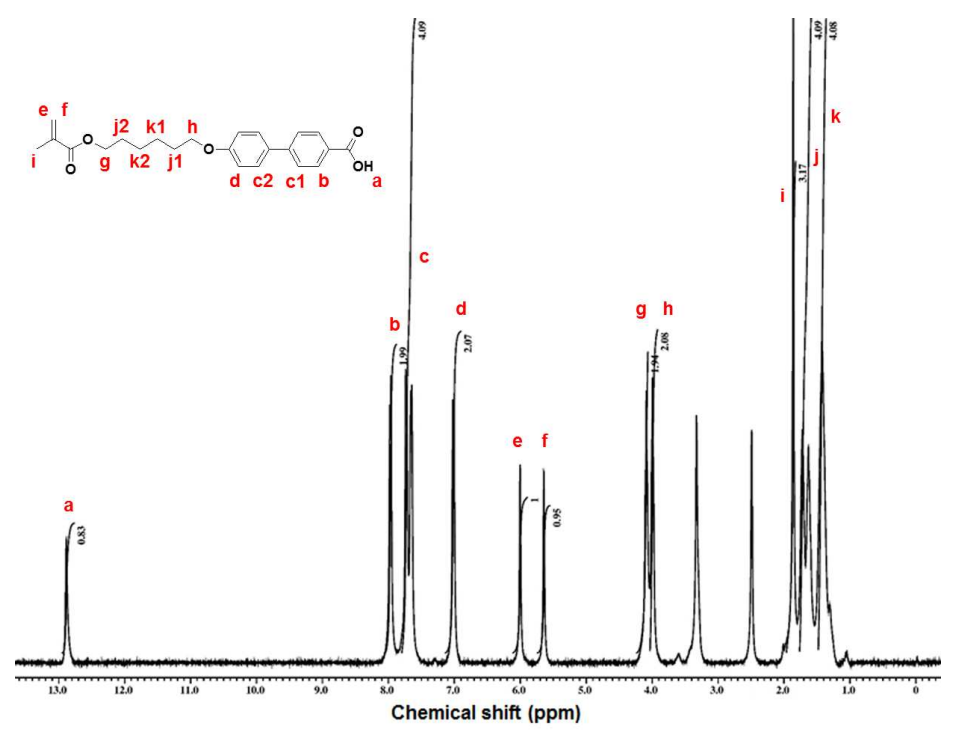

Figure S2. ${ }^{1} \mathrm{H}$ NMR spectrum of compound 1. 


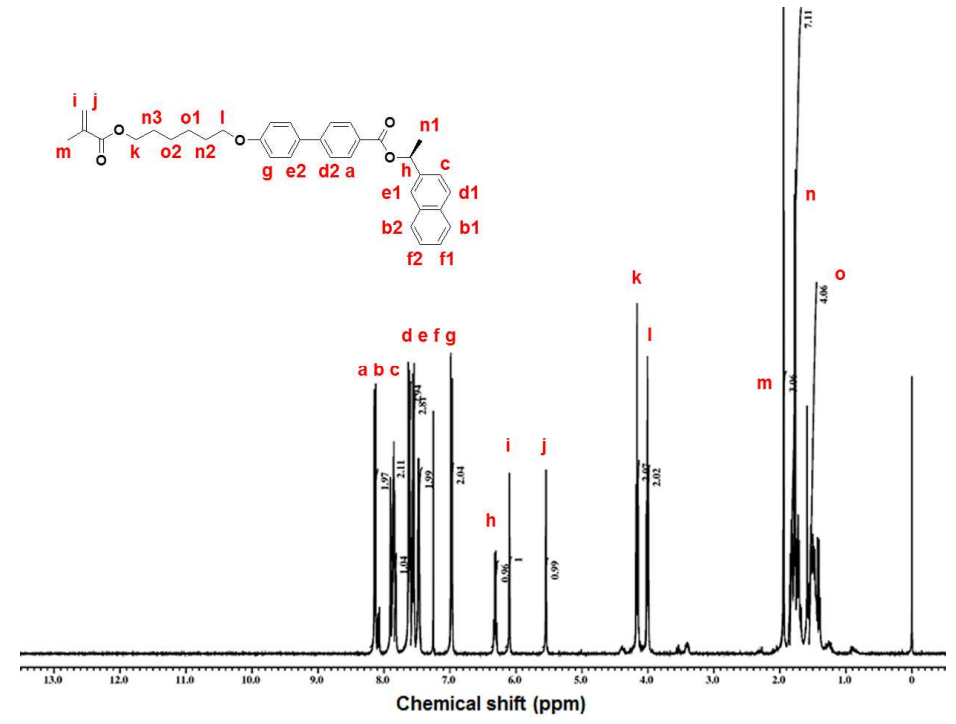

Figure S3. ${ }^{1} \mathrm{H}$ NMR spectrum of $\mathrm{BP}_{1} \mathrm{CRM}$.

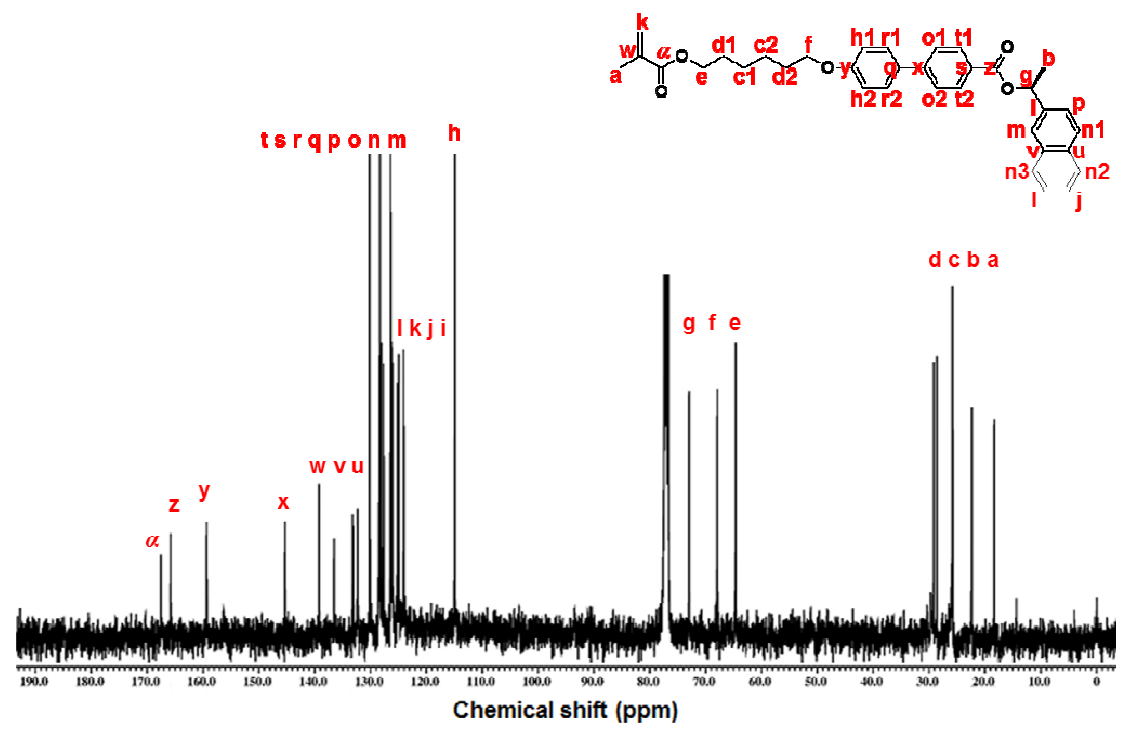

Figure S4. ${ }^{13} \mathrm{C}$ NMR spectrum of $\mathrm{BP}_{1} \mathrm{CRM}$. 


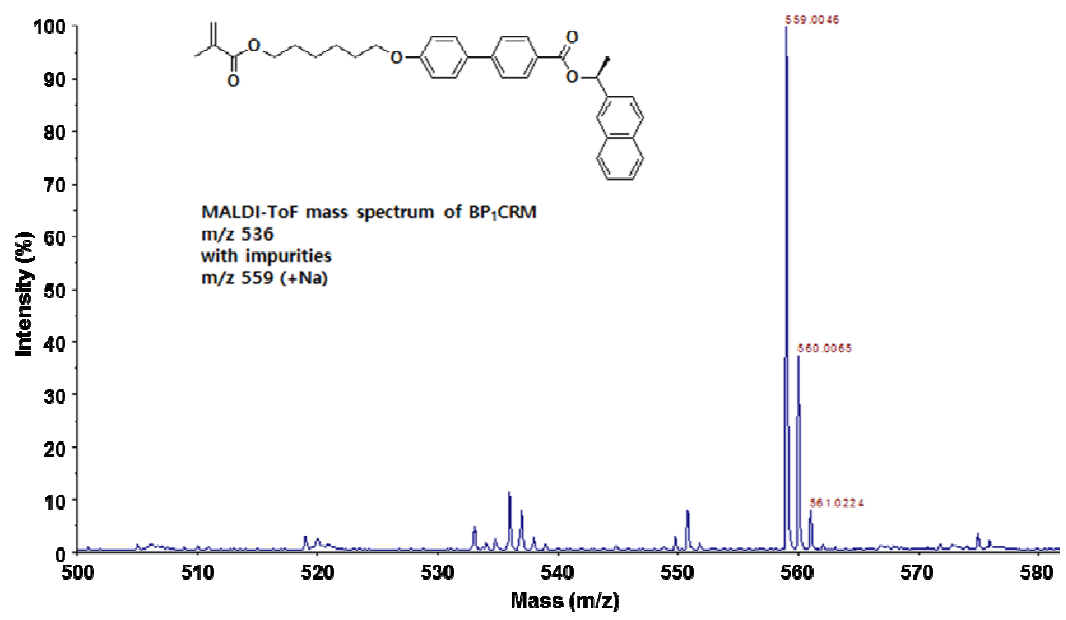

Figure S5. MALDI-ToF mass spectrum of $\mathrm{BP}_{1} \mathrm{CRM}$.

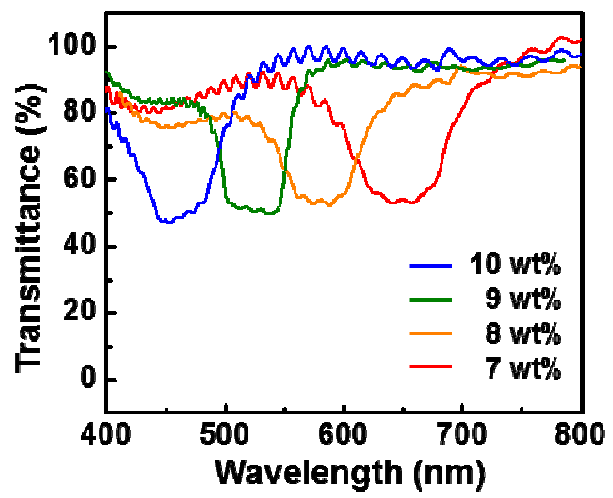

Figure S6. Reflection spectra consisting of $\mathrm{BP}_{1} \mathrm{CRM}$ with varying the concentration. 


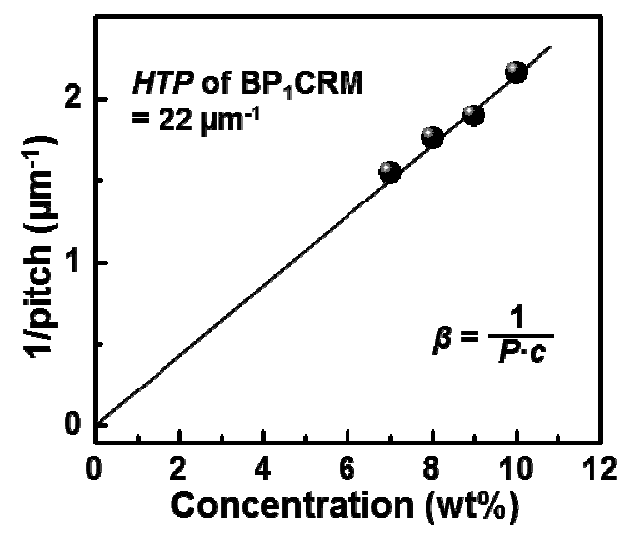

Figure S7. Helical pitch length $(P)$ and helical twisting power $(\beta)$ of CLC phase fabricated with $\mathrm{BP}_{1} \mathrm{CRM}$ as a function of its concentration $(c)$.

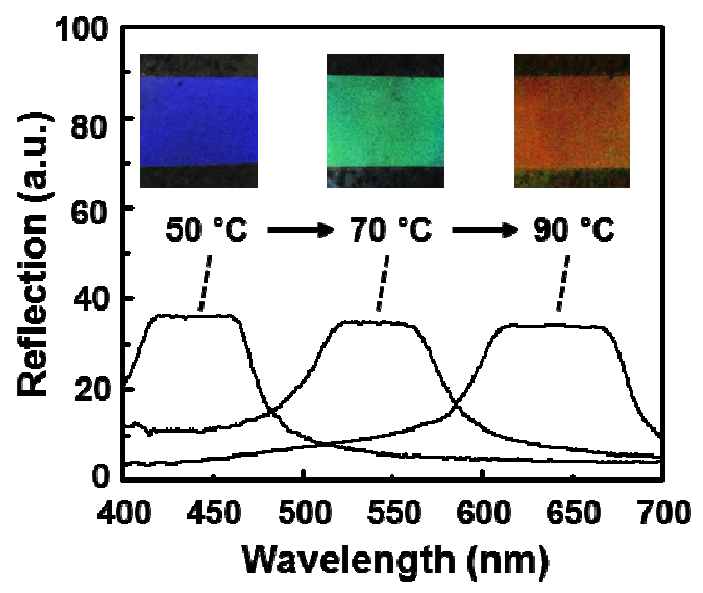

Figure S8. Macroscopic images and corresponding reflection spectra of the cell with $10 \mathrm{wt} \%$ $\mathrm{BP}_{1} \mathrm{CRM}$ and $90 \mathrm{wt} \% \mathrm{RM} 257$ upon heating. 


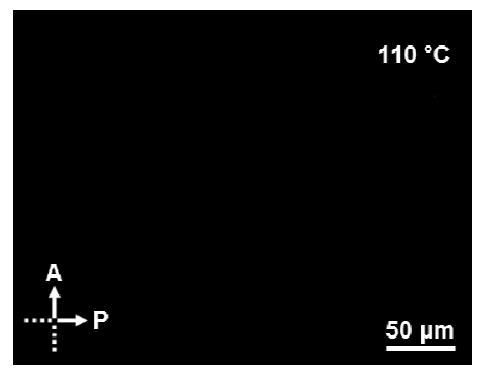

Figure S9. POM images of $10 \mathrm{wt} \% \mathrm{BP}_{1} \mathrm{CRM}$-doped CLC mixture at $110^{\circ} \mathrm{C}$.

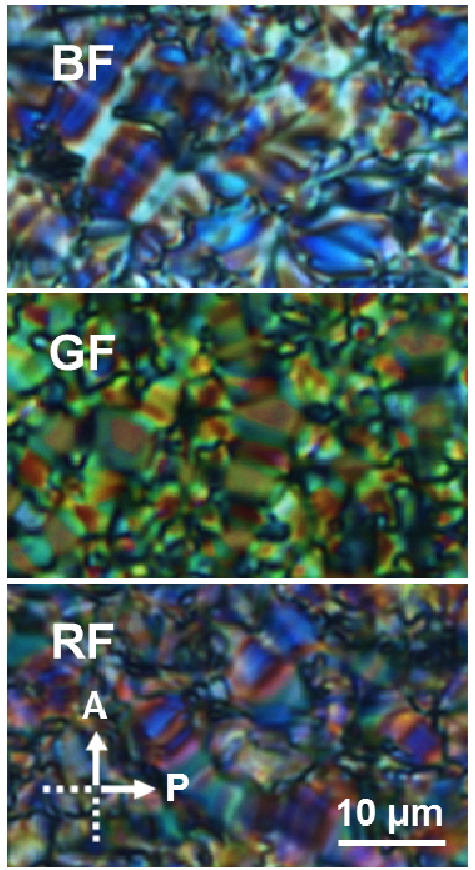

Figure S10. POM images of BF, GF, and RF, respectively. 


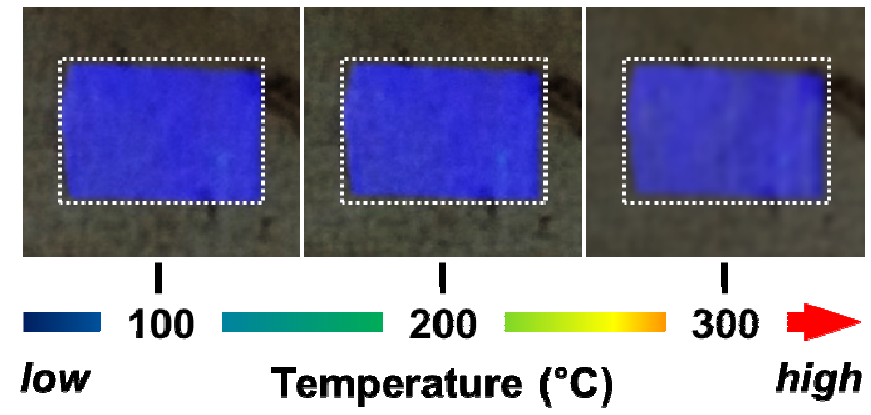

Figure S11. Macroscopic images of BF at different temperatures.

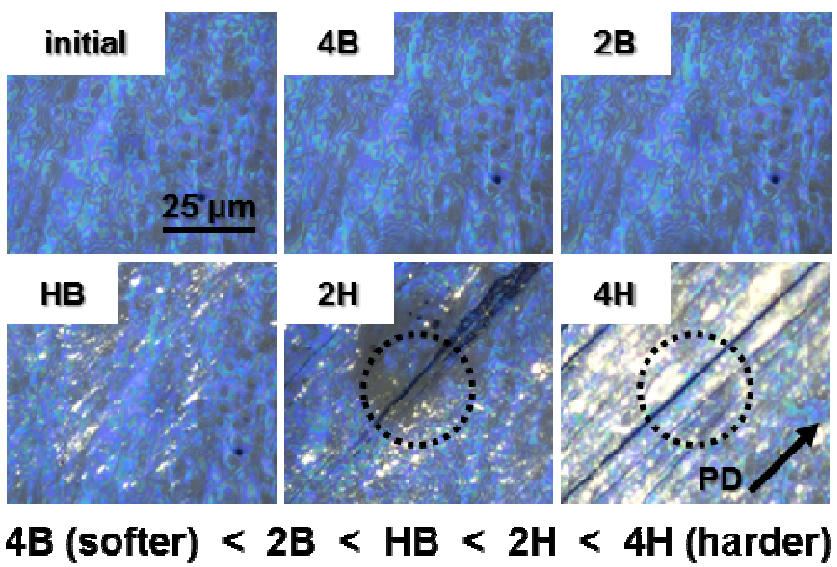

Figure S12. Optical textures of BF after scratch resistance test. 


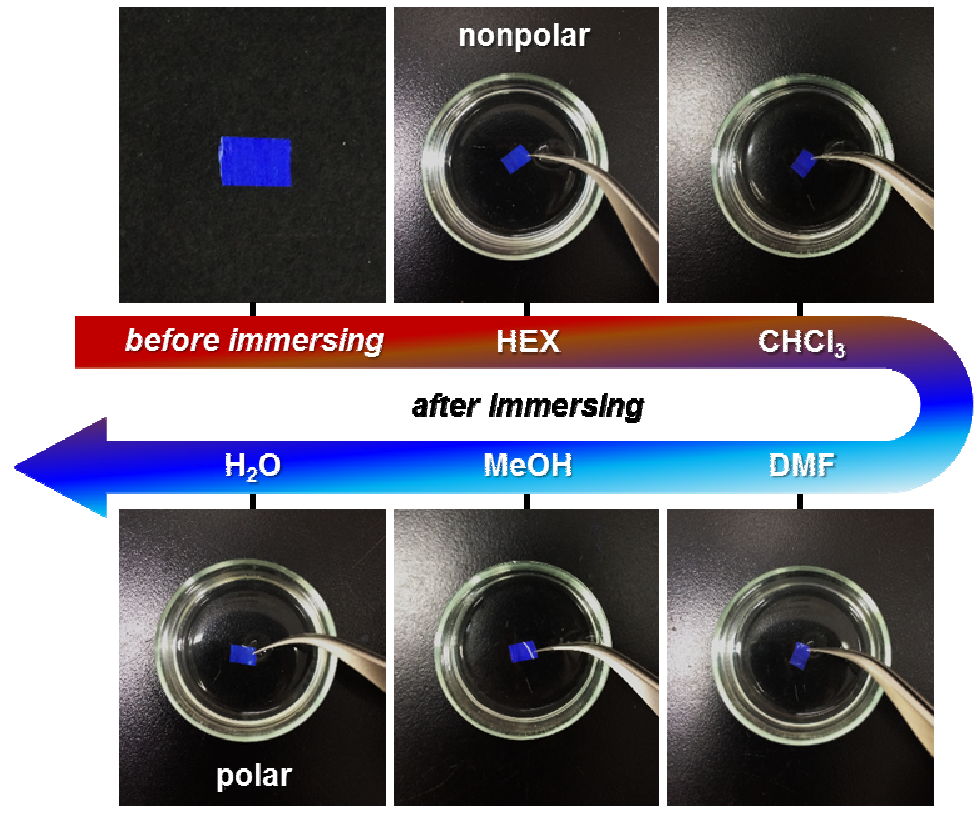

Figure S13. Photographs of BF in the various solvent for $30 \mathrm{~min}$.

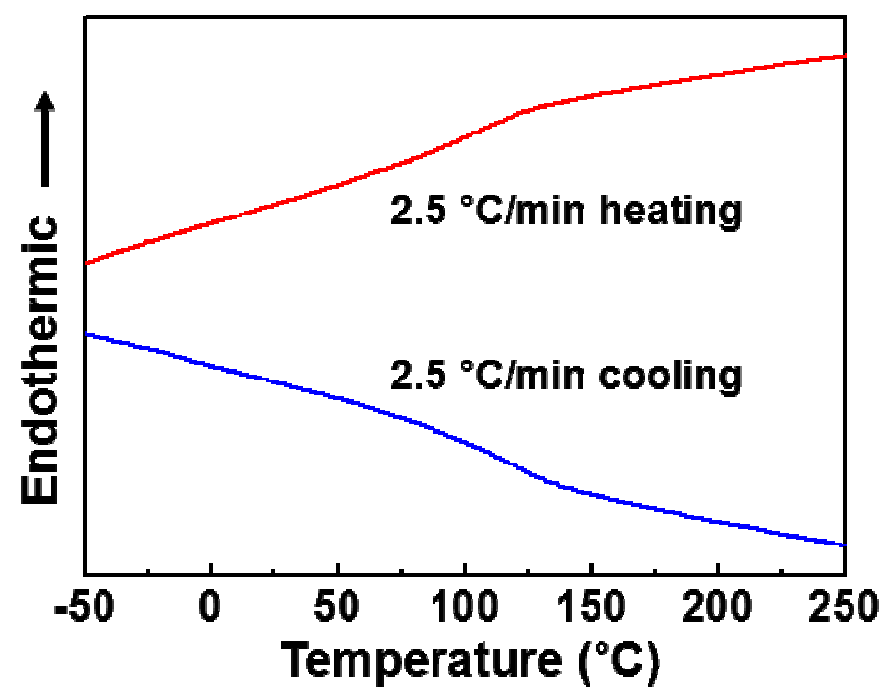

Figure S14. DSC thermograms of BF upon heating and subsequent cooling process. 